\title{
DESIGN OF GPS AND COMPASS HELMET VISUAL DATA USING MICROCONTROLLER FOR MARINE FORCE OF INDONESIAN NAVY
}

\author{
Endin Tri Hartanto, Erpan Sahiri, Agung Gunawan, M. Sigit Purwanto \\ Indonesian Naval Technology College, STTAL \\ Bumimoro-Moro Krembangan, Surabaya, 60178, Indonesia
}

\begin{abstract}
The Marines are a component of the combat forces owned by the Navy. In carrying out their duties as infiltration forces and landing forces, sophisticated equipment is needed to support each movement in terms of knowing the position of coordinates in the form of latitude longitude and compass direction to facilitate the movement of troops in carrying out operational tasks. For this reason, a tool was made to visually know the position of the latitude and longitude of the compass, making it easier for troops to carry out their duties both on the training ground and on the battlefield. This tool is in the form of a Design Combat Helmet for Visual Data Viewer GPS and Microcontroller-based Compass for the Navy Navy. This tool uses Arduino Mega Pro Mini 2560 as a microcontroller, V.KEL 2828U7G5LF as a GPS module, HMC5883L as a Compass module and Wemos Oled LCD $64 \times 480.66$ "as an analog data viewer. This tool has a working principle like Google Glass that can display data visually. How it works in order to display data visually is to use the reflection of a small mirror that will be enlarged using a convex lens or loop lens and then transmitted the reflection to a visual viewer that is placed in front of the eye. In order to get data in the form of latitude longitude and compass direction alternately a push button is used which is designed as a data selector switch or counter. In testing, this tool proved to be accurate in taking GPS data and compass direction after compared with equipment that has the same function. For the $V$. KEL2828U7G5LF GPS Module compared to FURUNO GPS and Google Map, while for the HMC5883L Compass module compared to the Android Compass Application.
\end{abstract}

Keywords: GPS data, Compass, Visual Combat Helmet

\section{INTRODUCTION}

The Indonesian Navy's Marine Corps Force is a combat force born on 15 November 1945 after the proclamation of the independence of the Republic of Indonesia. In his duty the Marines are to foster strength and operational readiness as a Navy amphibious landing force, infiltrate through the coast and other operations according to the TNI Commander's orders. Currently the Navy has pasmar 3 Marines, namely pasmar 1 in Jakarta, Pasmar 2 in Surabaya and pasmar 3 in Sorong, West Papua. Each Pasmar consisted of the Infantry Brigade, Artillery Regiment, Cavalry Regiment and Banpur Regiment.

In every combat operation or in combat training equipment carried by each personnel such as, SS-1 weapons, haversack and combat helmets, which are classified as heavy not to mention other supporting equipment namely communication equipment, binoculars, portable compasses, portable gps, and so forth. In each field of operation required speed in making decisions in terms of reading GPS data, reading the compass direction and the target distance. Or in the target reconnaissance the data required above without having to multiply the movements that are not needed for reconnaissance silence.

Based on the problems mentioned above so as not to reduce the preparedness of the troops themselves in retrieving GPS data and compass direction, then a tool based on a visual system is used, namely a Design of a Combat Helmet for Visual Data Viewer GPS and Compass Using Microcontrollers for Navy Marines

The design of the tool was inspired by an animated film which we then applied to a maritime support tool on duty. This application has been developed by a company called Google in 2014 and named Google Glass. Google glass technology has been widely adopted by several countries such as the United States of America for military purposes, the United Kingdom for military 
purposes and the security of the Queen of England, the State of China for police purposes to detect or spy on criminals, and the State of Brazil for security purposes in the world cup 2014. Indonesia has actually been developed by UGM computer engineering student Daniel Oscar Baskoro by creating a Quick Disaster application that is displayed visually on Google Glasses devices.

\section{RESEARCH METHODS}

\section{$2.1 \quad$ Research Design}

This research is an experiment that starts from an imagination which is then applied into innovation as a supporting tool for the marines in accordance with the background and formulation of the problem above. In this research, a merger of tools and data design will be performed displayed on a series of microcontroller modules.

The first step is to assemble an electronic circuit that is Arduino Mega Pro Mini 2560, GPS Module V.KEL2828U7G5LF, Compass Module HMC5883L, Oled LCD 64×48 0.66 "with input voltage from Hercules 18650 battery. The data are displayed into two parts of the LCD display, i.e. part

first the latitude and longitude data then the second part is the heading heading compass using the on / off push button as a counter. Then do some library merging and merging programs on the Arduino 1.8.5 application so that the program can be set up on the microcontroller permanently.

The second step is to make the chassing for the electronic circuit placement as concise as possible, especially in the most important part, the Oled LCD 64x48 0.66 ". So that the data display on the LCD is reflected by a mirror with an angle of $135^{\circ}$ and then forwarded by a convex lens or loop lens and then it can form an enlarged visual data. While the combat helmet is only a tool for supporting the placement of tools.

Next is the design of the GPS Combat Viewer and Compass Helmet Visual Design Helmet Builder Tool Using a Microcontroller for the Navy

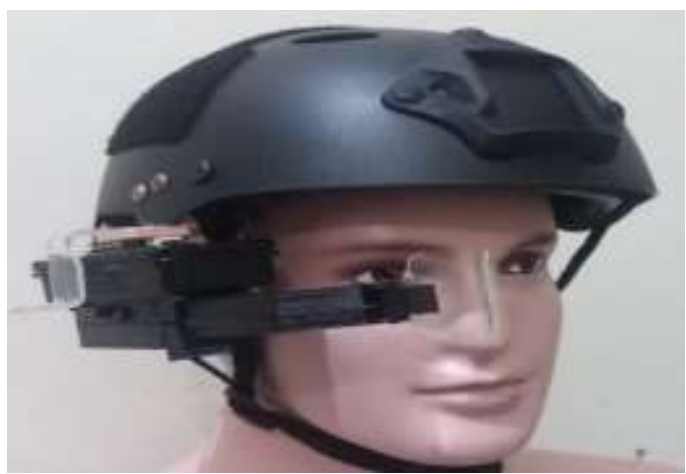

Figure 1.1: Desain Alat

\section{$2.2 \quad$ Research Design}

This research is a process that is carried out in stages, namely the design and planning of research, determine the focus of research, research time, data collection, analysis and present the results of research. Regarding the writing of the results of this study was done descriptively or through descriptions that describe and explain how the system works. The planning and design of this study is illustrated through a block diagram that displays GPS and Compass data with a push button that functions as a counter. For counter 1 , the data displayed is GPS data in the form of latitude and longitude. Whereas for counter 2 the data displayed is the compass heading. GPS digital data or the Kompas module digital data will be displayed analogically by an oled LCD which is a $64 \times 48$ matrix display. Then the data displayed will be reflected through a mirror with an angle of $135^{\circ}$ and will be enlarged with a convex lens so that the data displayed is magnified. The description of the research design can be described as follows through a system block diagram.

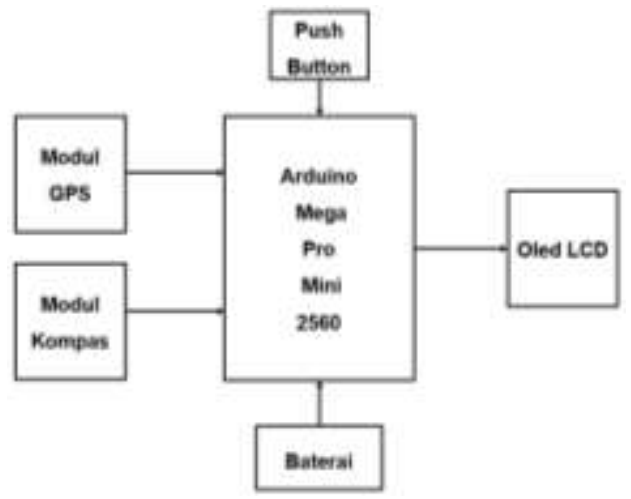

Figure 2.1: Tool Research Block Diagram 


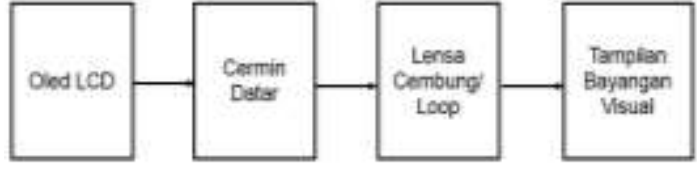

Figure 2.2: Visual System Research Block Diagram

\subsection{Research Flowchart}

From the flowchart above it can be explained that the flow of the system is when the voltage is entered then Arduino will initialize the GPS serial 2, initialize the Oled LCD, initialize the compass and the counter declaration. The next process is to activate GPS and compass and then wait until pin $17(\mathrm{RX})$ receives GPS data from satellites. If the receiver has received data from the satellite then the push button logic as a counter can be implemented. If the push button works as counter 1 , the GPS data will be received by serial buffer 2 then the buffer will select what data is used then display the GPS data that has been selected on the Oled LCD. But if not then the push button will work on counter 2, it will access the compass then display the compass data on the Oled LCD but if not then the process is complete.

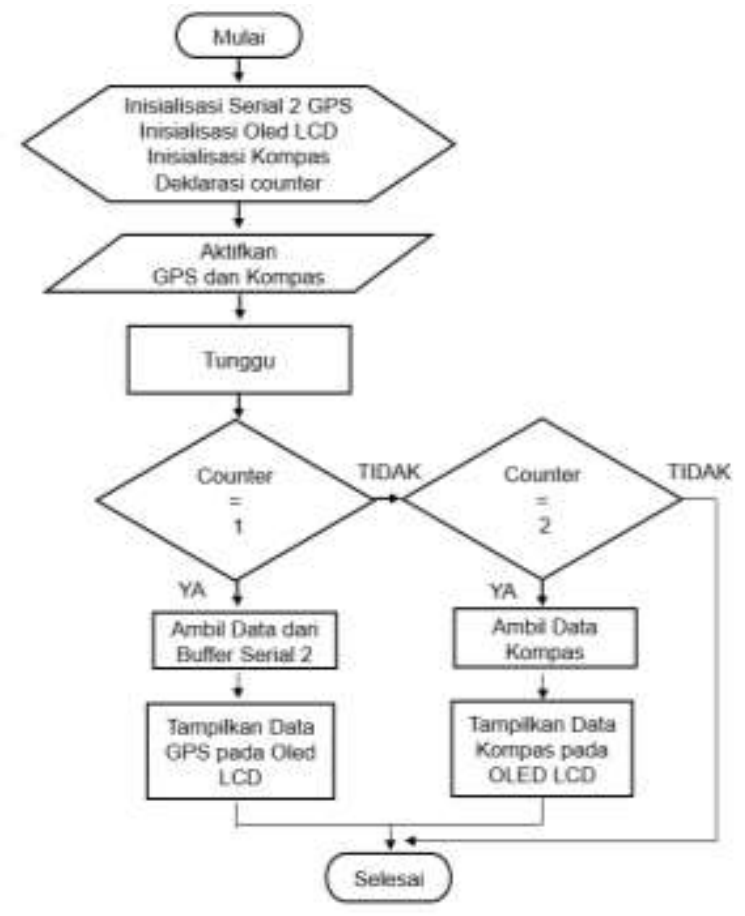

Figure 2.3: Research Flowchart

\section{RESULTS AND DISCUSSION}

Results and discussion regarding testing of the V.KEL 2828U7G5LF GPS module and the HMC5883L compass module that is compared with tools or applications that have the same working system. This works so that the module used is able to function properly, and measures the level of accuracy of the tools made. So that this design is suitable for users to use in accordance with its purpose.

\subsection{GPS Data Results and Testing}

On the results and discussion of GPS data testing the GPS module V. KEL2828U7G5LF is compared with GPS FURUNO and Google map applications. Here are the GPS data taken from the V.KEL GPS Module, FURUNO GPS and Google map that take location on the new Semampir dock in Surabaya :

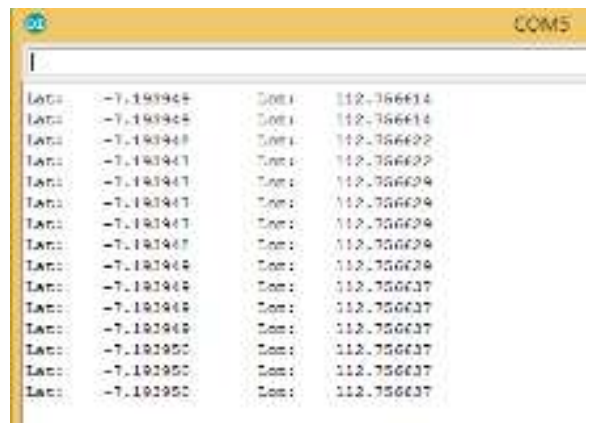

Figure 3.1: Serial GPS Monitor Data at Semampir Pier

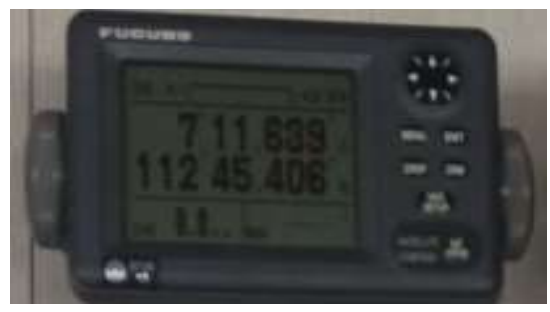

Figure 3.2 : Furuno GPS data on Semampir Pier 


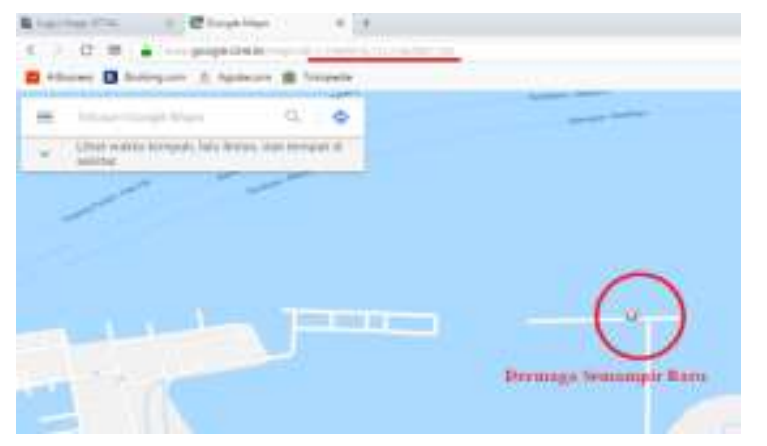

Figure 3.3: Google Map on Semampir Pier

From the picture above shows the difference between the data obtained by GPS V. KEL 2828U8G5LF, GPS Furuno and Google Map application. This is because the data received by the GPS V.KEL and the google map application is still in the form of decimal while for Furuno GPS it has been through conversion so that the data obtained in the form of degrees, minutes and seconds. The following calculation changes the GPS decimal data to degrees, minutes and seconds of GPS V. KEL2828U8G5LF and the google map application:

a. Calculation of GPSVKEL2828U8G5LF data conversion.

latitude data: -7.193950 , longitude data: 112.756637

Latitude of degree value is taken from integer value in front of comma:

$-7=$ degrees and $(-)=$ southern latitude, the degree value is $7^{\circ} \mathrm{LS}$

Latitude of minutes is taken from the integer value behind the comma and multiplied by 60 , so:

$0.193950 \times 60=11.637$

Then the minute value $=11$,

Latitude value of seconds is taken from fractions of minutes and multiplied by 60 then:

$0.637 \times 60=38.22$

Then the second value $=38$ "

Then the latency value is $7^{\circ} 11$ ' 38 "LS

Longitude of degree value is taken from interger value in front of comma:

$112=$ degrees and $(+)=$ east, the degree value is $112^{\circ}$ east

Longitude minute value is taken from the interger value behind the comma and multiplied by 60 then:

$0.756637 \times 60=45.392222$

Then the minute value $=45$,
Longitude value of seconds is taken from fractions of minutes and multiplied by 60 then:

$0.39822 \times 60=23.79$

Then the second value is 23 "

Then the longitudinal value is $112^{\circ} 45$ '23 "East

b. Calculation of GPS data conversion on google map.

latitude data: -7.194897, longitude data: 112.756288

Latitude of degree value is taken from integer value in front of comma:

$-7=$ degrees and $(-)=$ southern latitude, the degree value is $7^{\circ} \mathrm{LS}$

Latitude of minutes is taken from the integer value behind the comma and multiplied by 60 , so:

$0.194897 \times 60=11,693$

Then the minute value $=11$,

Latitude value of seconds is taken from fractions of minutes and multiplied by 60 then:

$0.693 \times 60=41.58$

Then the second value $=41^{\prime \prime}$

Then the latency value is $7^{\circ} 11^{\prime} 41^{\prime \prime L S}$

Longitude of degree value is taken from interger value in front of comma:

$112=$ degrees and $(+)=$ east, the degree value is $112^{\circ}$ east

Longitude minute value is taken from the interger value behind the comma and multiplied by 60 then:

$0,756288 \times 60=45,37728$

Then the minute value $=45$,

Longitude value of seconds is taken from fractions of minutes and multiplied by 60 then:

$0.37728 \times 60=22.63$

Then the second value is 22 "

Then the longitudinal value is $110^{\circ} 45^{\prime} 22$ "East

While data from the Furuno GPS has been converted into degrees minutes and seconds which is $7^{\circ} 11$ ' 639 "LS - $112^{\circ} 45^{\prime} 406$ " East, but for seconds still thousandths of a second multiplied by 60 (sixty) then divided by 1000 (one thousand) ) so that the result becomes 2 (two) digit degrees.

$\begin{array}{ll}\text { Furuno GPS latitude value } & =639 \times 60: 1000 \\ & =38,34 " \\ \text { Rounding value } & =38 " \\ \text { Furuno GPS longitude value } & =406 \times 60: 1000 \\ & =27,6 "\end{array}$


Rounding value

$=27$ "

So the longitude latitude of the Furuno GPS becomes $7^{\circ} 11^{\prime} 38^{\prime \prime}$ LS - $112^{\circ} 45^{\prime} 27^{\prime \prime}$ BT

So, from the conversion calculation data above can be made a table like below so it is easy to find out the differences in each GPS.

Table 1 Coordinate Comparison Data

\begin{tabular}{|c|l|c|c|}
\hline No & $\begin{array}{l}\text { Data retrieval } \\
\text { subject }\end{array}$ & $\begin{array}{c}\text { Latitude/ } \\
\text { Lintang }\end{array}$ & Longitude/Bujur \\
\hline 1. & $\begin{array}{l}\text { Modul GPS } \\
\text { V.KEL } \\
\text { 2828U8G5LF }\end{array}$ & $7^{\circ} 11^{\prime} 38^{\prime \prime}$ LS & $112^{\circ} 45^{\prime} 23^{\prime \prime}$ BT \\
\hline 2. & GPS Furuno & $7^{\circ} 11^{\prime} 38^{\prime \prime}$ LS & $112^{\circ} 45^{\prime} 27^{\prime \prime}$ BT \\
\hline 3. & Google Map & $7^{\circ} 11^{\prime} 41^{\prime \prime}$ LS & $112^{\circ} 45^{\prime} 22^{\prime \prime}$ BT \\
\hline
\end{tabular}

From the data above, what will be the subject of comparison is Furuno GPS because Furuno GPS is a GPS manufacturer that has been widely used both in the civilian and military world. Then the calculation of the difference is as follows:

Latitude Difference = Latitude GPS Furuno Latitude GPS V.KEL $=7^{\circ} 11^{\prime} 38^{\prime \prime}$ LS $-7^{\circ} \quad 11^{\prime}$ 38" LS

$$
=0^{\circ} 00^{\prime} 00^{\prime \prime} \text { (Absolut) }
$$

(Absolut)

Selisih Longitude = Longitude GPS Furuno - Longitude GPS V.KEL

$$
=112^{\circ} 45^{\prime} 27^{\prime \prime} \mathrm{BT}-112^{\circ}
$$

$45^{\prime} 23$ " BT

$$
\text { = } 000^{\circ} 00^{\prime} \text { 04" (Absolut) }
$$

Selisih Longitude = Longitude GPS Furuno - Longitude Google map

$$
=112^{\circ} 45^{\prime} 27^{\prime \prime} \mathrm{BT}-112^{\circ}
$$

45' 22" BT

$$
=000^{\circ} 00^{\prime} 05^{\prime \prime} \text { (Absolut) }
$$

So the GPS data received by the GPS module V. KEL2828U8G5LF compared to the Furuno GPS and Google Map application is absolute or precise in terms of degrees, minutes and seconds.

\subsection{Compass Data Results and Testing}

Testing the HMC5883L compass module is by comparing with the compass application on Android as well as the manual compass. By comparing the results of the HMC5883L compass data and the compass application on Android, you will know the accuracy of the compass heading data. Here are the comparison data between the HMC5883L compass module and the compass application on Android:

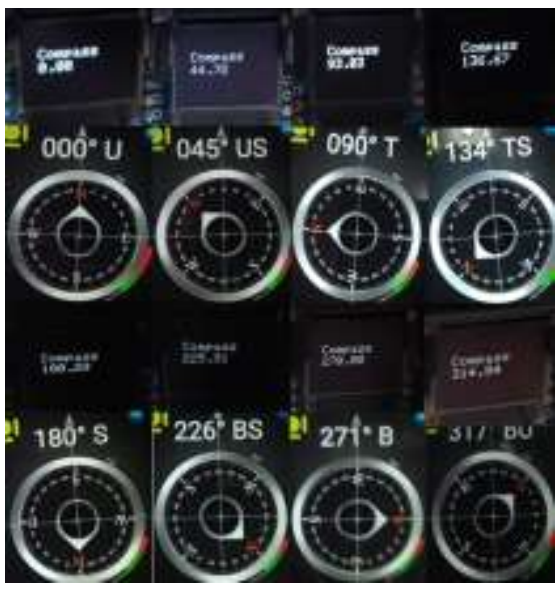

Figure 3.4: Compass Comparison Data

Table 2 Comparison Compass Data

\begin{tabular}{|c|c|c|c|}
\hline No. & $\begin{array}{c}\text { Large } \\
\text { Angle }\end{array}$ & $\begin{array}{l}\text { Compass } \\
\text { HMC5883L }\end{array}$ & $\begin{array}{l}\text { Compass } \\
\text { Android } \\
\text { Application }\end{array}$ \\
\hline 1. & $0^{\circ}$ & $000^{\circ}$ & $000^{\circ}$ \\
\hline 2. & $45^{\circ}$ & $44,72^{\circ}$ & $045^{\circ}$ \\
\hline 3. & $90^{\circ}$ & $93,03^{\circ}$ & $090^{\circ}$ \\
\hline 4. & $135^{\circ}$ & $136,67^{\circ}$ & $134^{\circ}$ \\
\hline 5. & $180^{\circ}$ & $180,29^{\circ}$ & $180^{\circ}$ \\
\hline 6. & $225^{\circ}$ & $225,91^{\circ}$ & $226^{\circ}$ \\
\hline 7. & $270^{\circ}$ & $270.00^{\circ}$ & $271^{\circ}$ \\
\hline 8. & $315^{\circ}$ & $314,54^{\circ}$ & $317^{\circ}$ \\
\hline
\end{tabular}

From the above table data it can be concluded that the heading of the HMC5883L compass module compared to the Android Compass Application is nearly accurate. 


\section{CONCLUSIONS AND SUGGESTIONS}

\subsection{Conclusion}

Design and Build of Combat Helmets with Visual Data Display and GPS Compass Using Microcontrollers for Navy Marines. This combat helmet can display GPS data in the form of latitude and longitude and Kompas heading data visually, which is useful for TNI Marines when conducting combat training exercises in the field. Based on the results of the design, testing and analysis during the preparation and manufacture of this final project, the following conclusions can be drawn:

a. This tool is printed using Teflon plastic material with a thickness of about $1 \mathrm{~mm}$ with a size adjusted to the dimensions of the Oled LCD $64 \times 480.66$ "then the electronic devices used are assembled in the chassing. To be used visually, the device is mounted on the right side of the ear which is attached to the bottom side of the combat helmet. To be able to display visuals, this chassing can be moved horizontally and the visual viewer in front of your eyes can be moved horizontally.

b. In order to get data alternately the push button is used as a counter or data selector, counter 1 is used to select GPS data in the form of latitude and longitude and counter 2 is used to select the compass heading data. The data displayed on the Oled LCD can be seen in the visual viewer by moving the visual viewer horizontally according to an angle of $135^{\circ}$.

\subsection{Suggestion}

Based on observations of the Design of Combat Helmets Visual Data Viewer GPS and Compass Using a Microcontroller for the Navy Navy, the following suggestions can be given:

a. In designing the tools for future research, it is expected to be simpler and smaller so that it is more comfortable to use in all activities.

b. The sensor features are expected to be more like people's body heat sensors, metal sensors or other sensors so that they can detect data from the enemy.

c. Oled LCD is expected to be smaller and display useful videos when combined with applications on Android.

d. This design and development are expected to be developed further which in the end can support operational activities in the field for the benefit of the Navy in particular as well as the $\mathrm{TNI}$ in general. As well as to reduce dependence on military products from abroad so that they can support the independence of the TNI Armament Main Tool.

\section{ACKNOWLEDGEMENT}

The authors greatly acknowledge the support from Naval Technology College, STTAL Surabaya Indonesia for providing the necessary resources to carry out this research work. The authors are also grateful to the anonymous reviewers and journal editorial board for their many insightful comments, which have significantly improved this article.

\section{REFERENCES}

Altwaijry, H., \& Moghimi, M. (2014). Recognizing Locations with Google Glass. Case Study, 1-8.

Baddeley, G. (2001, July 20). aprs.gids.nl. Retrieved from aprs.gids.nl: http://aprs.gids.nl/nmea/

Kadir, A. (2014). From Zero to a Arduino Pro. (T. A. Prabawati, Ed.) Melaka, Melaka, Malaysia: Andi Yogyakarta.

Maini, A. K., \& Agrawal, V. (2007). Satellite Technology Principles and Applications. Southern Gate, Chichester, England: John Wiley \& Sons, Ltd.

Singgih, H. (2017). Designing a GPS-Based Qibla Direction Indicator. Eltek Journal, 11.

Widya, L. (2013). Grounded Theory as a Research Method "Added Reality" in Fatahillah Museum. Journal of Electrical Engineering, 10.

xnp.com. (2018, April 29). Retrieved from i2C licensing information. 